\title{
IDEOLOGI KAPITALISME DALAM IKLAN ROKOK DJARUM 76 EDISI WANI PIRO: KAJIAN ANALISIS WACANA KRITIS
}

\author{
Reci Apreno ${ }^{1}$, Noermanzah ${ }^{2}$ \\ ${ }^{1,2}$ Program Studi Magister Pendidikan Bahasa Indonesia, Universitas Bengkulu \\ JIn. W.R. Supratman Kandang Limun, Kota Bengkulu, Indonesia \\ Email: reciapreno@gmail.com ${ }^{1}$,noermanzah@unib.ac.id ${ }^{2}$
}

\begin{abstract}
Abstrak
Perkembangan iklan saat ini semakin pesat sejalan dengan perkembangan teknologi yang semakin tidak terbendung. Sejatinya iklan merupakan media yang digunakan suatu perusahaan atau badan usaha untuk mempromosikan barang atau jasa yang memiliki bahasa yang bersifat persuasive dan memiliki ideologi kapitalisme. Namun, saat ini ada beberapa iklan yang tidak menggunakan bahasa yang membujuk, tetapi ingin memasukkan unsur kapitalisme, seperti iklan Djarum 76 yang akan dibahas dalam penelitian ini. Dalam penelitian ini akan mendeskripsikan ideologi kapitalisme dalam iklan rokok Djarum 76 edisi Wani Piro. Metode penelitian yang digunakan ialah metode analisis wacana kritis model Norman Fairclough. Objek atau data pada penelitian ini adalah wacana lisan yang terdapat pada iklan rokok Djarum 76 edisi Wani Piro. Teknik dalam pengumpulan data dilakukan dengan teknik dokumentasi yang bersumber dari YouTube. Dalam kegiatan analisis data sesuai dengan model Norman Fairclough terdapat tiga langkah analisis yaitu, analisis pada tataran teks, praktik wacana, dan praktik sosial budaya. Keabsahan data dilakukan dengan membercheck dan uji pakar wacana. Hasil penelitian ini menunjukkan bahwa kata-kata yang digunakan lebih kepada kata yang unik dan lucu, serta iklan Djarum 76 dikemas dengan bentuk wacana kritis seolah peduli dengan keadaan sosial masyarakat. Namun, di balik wacana kritis yang digunakan, terselubung ideologi yang bersifat kapitalisme sesuai dengan tujuan sebuah iklan yaitu mencari keuntungan dari produk yang dipromosikan.
\end{abstract}

Kata kunci: ideologi kapitalisme, iklan, analisis wacana kritis

\section{THE IDEOLOGY OF CAPITALISM IN THE DJARUM 76 CIGARETTE ADVERTISEMENT EDITION OF WANI PIRO: STUDY OF CRITICAL DISCOURSE ANALYSIS}

\begin{abstract}
The development of advertising is currently growing rapidly in line with technological developments that are increasingly unstoppable. Indeed, advertising is a medium used by a company or business entity to promote goods or services that have a persuasive language and have an ideology of capitalism. However, currently there are several advertisements that do not use persuading language, but want to incorporate elements of capitalism, such as the Djarum 76 ad that will be discussed in this study. This research will describe the ideology of capitalism in the Djarum 76 cigarette advertisement edition of Wani Piro. The research method used is the Norman Fairclough model of critical discourse analysis. The object or data in this study is the oral discourse contained in the Djarum 76 cigarette advertisement edition of Wani
\end{abstract}


Piro. The technique in collecting data is done by documentation technique sourced from YouTube. In the data analysis activities in accordance with the Norman Fairclough model there are three steps of analysis namely, analysis at the level of the text, discourse practices, and socio-cultural practices. Data validity is done by member checking and expert discourse test. The results of this study indicate that the words used are more unique and funny words, and the Djarum 76 advertisement is packaged with a form of critical discourse as if concerned with the social conditions of the community. However, behind the critical discourse that is used, veiled an ideology that is capitalism in accordance with the purpose of an advertisement that is looking for profit from the product being promoted.

Keywords: ideology of capitalism, advertising, critical discourse analysis

\section{A. Pendahuluan}

Keberhasilan pemasaran produk pada era new normal sangat ditentukan pada kualitas dan kuantitas iklan. Iklan yang menarik dan unik akan mendapatkan perhatian dari konsumen. Iklan bisa bersifat berita atau pemberitahuan yang berisi bujukan, rayuan, dan dorongan terhadap suatu barang atau jasa yang ditawarkan (Saputra \& Widyatmoko, 2019:289-290). Sejatinya iklan memiliki beberapa jenis sesuai dengan media yang digunakannya, seperti pada media cetak yang berbentuk tulisan, dan pada elektronik biasanya berbentuk lisan atau audiovisual (Mahartika, 2019:1). Perkembangan iklan bermula pertama kali pada tahun 1472 masih dalam bentuk poster yang memuat buku doa-doa gereja, selanjutnya pada tahun 1650, salah satu surat kabar di London mulai menerbitkan berbagai iklan (Elevate, 2016:1).

Semenjak saat itu perkembangan iklan semakin meluas hingga ke penjuru dunia, hingga ke Indonesia. Di Indonesia perkembangan iklan sudah ada semenjak zaman penjajahan sekitar tahun 1619 di Kota Batavia. Saat itu, iklan digunakan sebagai media untuk menginformasikan pesan-pesan pemerintahan dan perdagangan (Setianingrum, 2019:74). Hal tersebutlah yang melandasi terbentuknya iklan di Indonesia yang mana berawal dari bentuk tulisan berkembang menjadi audiovisual sesuai dengan perkembangan teknologi seperti sekarang ini.

Dengan berkembangnya teknologi informasi, bentuk iklan semakin menjadi bagus dari bentuk tulisan menjadi gambar hingga menjadi audiovisual. Pada awalnya inovasi pada iklan pertama kali dilakukan oleh Benyamin Franklin yang mengubah iklan dari bentuk tulisan menjadi gambar dengan efek-efek yang 
menawan (Tohir, 2016:35-36). Dia memvisualisasikan tulisan ke dalam bentuk gambar sehingga iklan bukan hanya berbentuk tulisan, tetapi berbentuk gambar yang seolah-olah berbicara (Darmawan, 2006:103-114).

Dengan inovasi yang dilakukan oleh Benyamin Franklin mempengaruhi bentuk iklan sampai dengan sekarang. Dewasa ini iklan lebih banyak berbentuk visual dan audiovisual karena dengan menggunakan bentuk visual dan audiovisual akan lebih efektif dalam menarik perhatian para konsumen terhadap produk yang dipromosikan (Utama, 2018:44). Dengan iklan yang berbentuk visual atau audiovisual bukan berarti menghilangkan bahasa dalam iklan, namun bahasa yang berbentuk tulisan diubah menjadi bentuk lisan, hal tersebut dilakukan karena sesuai dengan kebiasaan masyarakat saat ini yang mana lebih suka terhadap sesuatu yang bersifat visual.

Hingga saat ini belum ada aturan yang baku dalam sebuah iklan, sehingga bahasa dalam iklan sering kali tidak memperhatikan penggunaan bahasa Indonesia yang baik dan benar, dan kebanyakan bahasa yang digunakan bersifat bahasa sehari-hari (Ariyana, 2019:118-119). Sebaiknya bahasa dalam iklan mengandung kata-kata bujukan atau rayuan yang dirangkai menjadi kalimat persuasif yang tersurat dan tersirat sehingga konsumen membeli produk yang diiklankan (Zamzani dkk., 2017:250; Noermanzah, 2017). Dengan demikian, dapat dikatakan bahwa bahasa dalam iklan yang baik harus bersifat persuasif yang retoris (Noermanzah dkk., 2019). Namun, dengan perkembangan zaman saat ini hal itu kurang efektif untuk meningkatkan daya beli masyarakat. Saat ini masyarakat atau konsumen lebih aktif dengan hal-hal baru dan unik. Seperti yang berhubungan langsung atau yang sedang hangat terjadi di tengah masyarakat.

Salah satu produk yang menggunakan kata-kata yang unik dan lucu serta selalu melakukan parodi yaitu, Djarum 76. Dalam iklannya Djarum 76 selalu memiliki ciri khasnya tersendiri, yang mana setiap iklannya selalu ada yang berperan sebagai jin yang bisa mengabulkan permohonan. Seperti dalam iklan Djarum 76 yang berjudul "Wani Piro". Dalam iklan tersebut banyak menggunakan kata-kata yang unik serta memiliki makna yang mendalam, yang sesuai dengan keadaan masyarakat saat ini. Dalam iklan tersebut dapat mengungkapkan 
keadaan sosial, budaya, politik, dan lain-lain. Hal tersebutlah yang membedakan iklan Djarum 76 dengan iklan lainnya, seperti yang kita ketahui bahwa iklan tersebut selalu berisi kritik sosial. Dengan demikian, iklan rokok Djarum 76 menunjukkan produk rokok yang peduli dan kritis dengan kondisi masyarakat.

Apakah betul sebuah produk rokok benar-benar peduli dengan keadaan masyarakat saat ini? Hal tersebut akan peneliti bahas dalam penelitian ini dengan menggunakan analisis wacana kritis. Pada dasarnya critical discourse analysis digunakan untuk melihat atau menggali makna-makna yang terkandung dalam sebuah wacana dengan memperhatikan konteks wacana secara kritis (Eriyanto, 2006:5). Sejalan dengan tersebut A.S Hikam (dalam Eriyanto, 2001:4) ada beberapa hal yang harus diperhatikan dalam kegiatan analisis wacana kritis yaitu, positivisme, empiris, konstruktivisme, dan kritis.

Darma (2009:15) menjelaskan AWK bukan hanya sebagai alat untuk menganalisis bahasa dengan memperhatikan kaidah bahasa saja, tetapi juga dapat digunakan dalam analisis yang lebih luas lagi dengan memperhatikan konteks suatu wacana. Sejalan dengan hal itu, Jorgensen \& Phillips (2007) menyatakan bahwa dalam pandangan AWK menyajikan cara-cara yang dapat dipakai dalam kegiatan analisis wacana dengan memperhatikan hubungan wacana dengan keadaan sosial masyarakat (Noermanzah, 2018). Dengan demikian, analisis wacana kritis dapat digunakan untuk melihat atau menganalisis wacana publik.

Secara singkat, dalam penelitian ini akan mendeskripsikan bentuk dan rangkaian kata yang digunakan dalam iklan. Dengan demikian, ditemukan bentuk pola pilihan kata dalam wacana iklan yang dapat menarik perhatian konsumen, sehingga dapat diketahui apa yang mendasari iklan tersebut atau apa ideologi di balik kritisnya iklan Djarum 76 edisi "Wani Piro". Ada beberapa penelitian yang relevan dengan penelitian ini seperti yang dilakukan oleh Asnidar (2018) dengan judul Analisis Wacana Kritis Operator Seluler dengan hasil penelitian menunjukkan penggunaan kata bersifat tidak baku, dalam penelitian tersebut ditemukan bahwa adanya persaingan antara operator satu dengan yang lainnya dengan menggunakan bahasa untuk saling menyudutkan pesaingnya. 
Berdasarkan penjabaran di atas terlihat bahwa perbedaan penelitian ini dengan penelitian yang dilakukan oleh Asnidar (2018) yang pertama yaitu objek penelitiannya. Selanjutnya, penelitian ini melihat penggunaan kata yang digunakan oleh operator seluler untuk saling menyindir pesaingnya. Sedangkan penelitian yang penulis lakukan ialah bukan hanya untuk melihat bentuk kata yang digunakan, tetapi juga untuk melihat apa yang mendasari terbentuknya teks atau ideologi kapitalisme dari wacana iklan tersebut. Untuk itu, penelitian ini akan menjawab rumusan masalah "Bagaimanakah ideologi kapitalisme dalam iklan Rokok Djarum 76 edisi Wani Piro dengan menggunakan kajian analisis wacana kritis? Dengan harapan dapat melihat makna sebenarnya tentang tujuan ideologi kapitalisme dalam sebuah iklan. Selain itu, hasil penelitian ini juga diharapkan dapat dijadikan salah satu contoh kajian analisis wacana kritis pada Matakuliah Analisis Wacana pada perguruan tinggi.

\section{B. Metode Penelitian}

Metode yang digunakan dalam penelitian ini adalah metode analisis wacana kritis dengan model Norman Fairclough (Fairclough, 1995:9; Indah \& Bakti, 2017:125). Teknik pengumpulan data dilakukan dengan teknik dokumentasi, yaitu berupa rekaman iklan Djarum 76 yang berbentuk lisan yang ditranskripsikan menjadi tulisan yang bersumber dari YouTube.

Analisis data pada penelitian ini dilakukan dengan analisis wacana kritis model Norman Fairclough, dalam analisis wacana kritis model Norman Fairclough (Eriyanto, 2006:327) yang memiliki tiga langkah analisis sebagai berikut.

1. Deskripsi

Pada tahap ini analisis dilakukan hanya sebatas melihat bentuk penggunaan bahasa atau kata-kata dalam sebuah wacana atau teks iklan tanpa memperhatikan aspek lain, seperti konteksnya.

2. Interpretasi

Pada bagian ini penulis menganalisis teks iklan dan menafsirkannya dengan menghubungkan teks dengan konteks situasi wacana. 


\section{Eksplanasi}

Pada bagian terakhir ini penulis menganalisis hasil tafsiran yang telah dilakukan pada tahap interpretasi serta dikaitkan dengan sosial budaya masyarakat pengguna iklan rokok Djarum 76, sehingga akan ditemukan alasan terbentuknya wacana tersebut.

Dari ketiga tahapan analisis tersebut maka akan ditemukan apa ideologi yang mendasari terbentuknya wacana dalam iklan Djarum 76 edisi "Wani Piro". Selain itu juga, analisis data dilakukan dengan tiga tataran, yaitu 1) teks (text), (2) praktik wacana (discourse practice), (3) praktik sosial budaya (sociocultural practice) (Fairclough, 1995:98).

Uji keabsahan data dilakukan dengan cara membercheck dan uji pakar wacana. Membercheck dilakukan dengan mengecek hasil analisis dikaitkan dengan teori yang digunakan. Kemudian, hasil analisis data juga divalidasi oleh pakar analisis wacana sehingga diharapkan hasil penelitian dapat dipertanggungjawabkan keilmiahannya.

\section{Hasil Penelitian dan Pembahasan}

\section{Hasil Penelitian}

Djarum 76 adalah salah satu perusahan rokok tertua dan terbesar di Indonesia. Di beri nama Djarum 76 karena pertama kali diperkenalkan ke publik pada tahun 1976. Selain telah banyak memproduksi jenis rokok di Indonesia, Djarum 76 juga telah memasuki ranah lain, seperti dalam dunia olahraga menjadi sponsor, pada dunia pendidikan pemberian beasiswa, dan tidak ketinggalan di dunia periklanan sebagai media promosi produknya. Berdasarkan hal tersebut maka, data dalam penelitian ini ialah wacana lisan iklan Djarum 76 edisi "Wani Piro" dengan kajian menggunakan analisis wacana kritis.

Hakikatnya analisis wacana kritis tidak hanya melihat teks dari sudut pandang kosakata atau struktur bahasa saja, namun dapat lebih luas lagi, seperti konteks yang mempengaruhi terbentuknya suatu teks atau tujuan terbentuknya teks tersebut. Hal tersebut sejalan dengan pendapat Darma (2009) critical discourse analysis bukan hanya sebagai alat untuk menganalisis bahasa dengan 
memperhatikan kaidah bahasa saja, tetapi juga dapat digunakan dalam analisis yang lebih luas lagi dengan memperhatikan konteks suatu wacana. Untuk menemukan dan melihat apa yang mendasari atau apa yang melatarbelakangi ideologi terbentuknya iklan Djarum 76 edisi "Wani Piro" maka penulis menggunakan analisis wacana kritis model Norman Fairclough yang memiliki tiga tahapan analisis yaitu, deskripsi, interpretasi, dan eksplanasi.

Hasil penelitian ini menunjukkan bahwa dalam wacana iklan Djarun 76 edisi "Wani Piro" ditemukan bentuk bahasa yang digunakan terbilang unik dan menarik serta bahasa yang digunakan bersifat persuasif, dan bisa dikatakan bahasa yang digunakan dalam wacana iklan tersebut bersifat kritis terhadap keadaan sosial saat ini. Dimana pada wacana iklan Djarum 76 edisi "Wani Piro" terdapat sindiran terhadap praktik KKN yang semakin marak di negeri ini yang dibalut dengan parodi-parodi yang lucu sehingga hal tersebut dapat menarik perhatian masyarakat.

Pada iklan Djarum 76 terdapat bahasa yang lucu dan bersifat mengeritik keadaan sosial saat ini seperti "wani piro" sesuai dengan judul dari iklan tersebut. Iklan Djarum 76 yang berjudul "Wani Piro" ini bertempat di sebuah kantor, menceritakan seorang pria yang datang ke kantor tersebut untuk mengurus administrasi. Berikut ini wacana iklan Djarum 76 edisi "Wani Piro" yang telah ditranskripkan ke dalam bentuk deskripsi wacana tulis beirkut.

\footnotetext{
Saat pria tersebut tiba di sebuah kantor dia bertemu dengan seorang staf. Kemudian, staf tersebut memeriksa surat-surat yang dibawanya. Setelah staf itu memeriksanya dia tidak berbicara dan langsung menyerahkan berkas tersebut kepada pria itu sambil memainkan jari tangannya pertanda meminta uang. Kemudian, pria tersebut langsung beranjak sembari kesal dan menggerutu.

"Dasar rampok" Tibanya di luar, pria tersebut tidak sengaja menendang sebuah lampu tua dan tiba-tiba keluar sesosok laki-laki yang mengenakan baju khas Jawa, kemudian langsung mengatakan "Ku beri satu permintaan", tanpa pikir panjang pria yang masih kesal itu langsung mengatakan:

"Mau korupsi, pungli, sogokan ilang dari muka Bumi, Iso Jin?" Kemudian Jin yang memakai blangkon tersebut menjawab "Iso diatur, Wani Piro" sambil tertawa. Kemudian, pria tersebut hanya terdiam, dan pada akhir iklan terdapat logo rokok Djarum 76.
}

Silampari Bisa: Jurnal Penelitian Pendidikan Bahasa Indonesia, Daerah, dan Asing Vol. 3, No. 1, 2020 


\section{Pembahasan}

Berdasarkan hasil penelitian yang dipaparkan di atas bahwa dalam iklan Djarun 76 edisi "Wani Piro" mengandung pesan yang beragam serta disajikan secara unik dan menarik yang bertujuan menyampaikan ideologi kapitalisme secara tersirat. Hal ini sesuai pendapat Saputra \& Widyatmoko (2019:289-290) dan Utama (2018:44) bahwa iklan bertujuan menawarkan suatu produk dalam bentuk audiovisual sehingga lebih efektif dalam menarik perhatian para konsumen terhadap produk yang dipromosikan.

Dapat dilihat bahwa iklan Djarum 76 menggunakan bahasa yang tidak biasa jika dibandingkan dengan iklan-iklan rokok pada umumnya. Hal tersebut terlihat pada judulnya "Wani Piro" ungkapan dalam bahasa Jawa itu sangat bermakna dalam serta mengandung satire dan kritik sosial, sekaligus mengandung tawa. Karena apabila diucapkan kita seolah menertawakan budaya korupsi yang membumi di negeri tercinta kita ini. Kata-kata itu selalu terasa menggelikan pada saat setiap permintaan diiringi dengan pamrih. Hal itu yang membedakan iklan Djarum 76 dengan iklan lainnya, karena kebanyakan iklan rokok biasanya menggunakan bahasa yang mengajak atau membujuk serta dibintangi oleh pria-pria kekar yang mendaki gunung melewati lembah.

Namun pada iklan Djarum 76 lebih berbentuk parodi dan banyak sindiran di dalamnya. Hal tersebut membuat perhatian masyarakat terfokus terhadap iklan tersebut yang mendorong pemikiran masyarakat atau konsumen bahwa produk rokok Djarum 76 memiliki kepedulian terhadap gejolak sosial yang terjadi di masyarakat. Dengan demikian, produk yang ditawarkan menjadi meningkat penjualannya.

Berdasarkan pemaparan di atas, iklan Djarum 76 veri "Wani Piro" tidak menggunakan kata-kata yang bersifat mengajak untuk membeli produk mereka, melainkan pesan yang lebih luas seperti politik, kebangsaan, persatuan, dan kesatuan bangsa. Namun, apakah sebenarnya suatu produk tersebut benar-benar peduli dengan gejolak yang terjadi di masyarakat saat ini. Untuk mengetahui hal tersebut harus melihat lebih dalam lagi, bukan hanya dari teks melainkan konteks serta latar belakang terbentuknya iklan tersebut. Jika dilihat kata-kata yang 
digunakan dalam iklan Djarum 76 memang tidak ada yang bersifat persuasif, namun secara tersirat bersifat persuasif. Seperti apabila diperhatikan pemeran utama dalam iklan tersebut yang berperan sebagai Jin selalu memakai baju adat Jawa yang berwarna kuning termasuk dalam iklan Djarum 76 edisi "Wani Piro".

Warna kuning selalu digunakan karena warna utama dari rokok Djarum 76, selain itu selalu ada logo Djarum 76 di akhir iklan. Dengan begitu kata-kata yang seolah mengkritisi keadaan sosial saat ini hanyalah strategi pemasaran agar masyarakat atau konsumen menganggap bahwa Djarum 76 peduli dan kritis terhadap phenomena sosial saat ini. Namun, tujuannya tetaplah satu yaitu untuk menunjukkan produk yang dipromosikan agar selalu mendapatkan keuntungan.

Berdasarkan penjelasan di atas dapat dikatakan bahwa iklan Djarum 76 edisi "Wani Piro" didasari oleh ideologi kapitalis. Hal ini karena tujuan dari pembuatan iklan tersebut hanyalah untuk mempromosikan produknya dengan cara membangun mindseat masyarakat bahwa Djarum 76 peduli dengan keadaan sosial saat ini, tetapi kenyataannya iklan tetaplah ikan yang digunakan para produsen untuk menarik konsumen. Hal tersebut sejalan dengan penelitian yang dilakukan oleh (Pertiwi, 2008) menyatakan bahwa iklan merupakan alat atau media yang bertujuan untuk menawarkan barang atau jasa demi kepentingan bisnis.

Selanjutnya, Hiariej (2006) menyatakan prinsip keadilan yang dianut oleh sistem ekonomi kapitalis adalah setiap orang menerima imbalan berdasarkan prestasi karyanya. Dengan demikian, sudah jelas bahwa suatu karya yang memiliki kepentingan ekonomi seperti iklan merupakan karya yang diciptakan untuk menarik konsumen. Oleh karena iklan tersebut dibalut dengan kata-kata yang kritis sehingga mendorong simpati para konsumen, seperti dialog berikut "Mau korupsi, pungli, sogokan ilang dari muka Bumi, Iso Jin?" Dialog tersebut terdapat dalam iklan Djarum 76 edisi "Wani Piro" yang bermakna persuasif seolaholah Djarum 76 memahami kondisi masyarakat sekarang sehingga Djarum menawarkan solusi terhadap masalah tersebut yaitu menggunakan rokok Djarum 76 . 


\section{Simpulan}

Iklan Djarum 76 mengandung kata-kata yang unik jika dilihat dari kebiasaan iklan lain dalam menggunakan bahasa. Dalam iklan Djarum 76 lebih menunjukkan bahasa daerah yang mana apabila didengar akan selalu teringat. Selain itu, iklan Djarum 76 lebih bersifat parodi sehingga para penonton akan tertawa saat melihatnya, memang sebuah parodi adalah kepalsuan, tetapi kepalsuan yang didasari dari kebenaran yang terjadi di negara tercinta ini.

Dalam iklan Djarum 76 mengambarkan bahwa masih berkembangnya budaya yang tidak baik dilakukan oknum pemerintah. Iklan Djarum 76 cenderung menghilngkan dan menghindari efek negatif pada rokok, sehingga masyarakat atau konsumen terpedaya dalam kemasan iklan yang unik dan kritis terhadap kehidupan masyarakat. Namun, sebagus apapun dan semenarik apapun sebuah iklan, akan ada suatu tujuan di balik iklan tersebut, yang paling utama yaitu agar penjualan produk yang diiklankan terjual. Hal tersebut merupakan strategi para pemilik perusahaan dalam memasarkan produknya. Setiap terbentuknya suatu wacana kritis akan ada kepentingan dan ideologi yang mendasarinya.

\section{Daftar Pustaka}

Ariyana, A. (2019). Analisis Bahasa Pijin pada Iklan Pertelevisian Indonesia. Silampari Bisa: Jurnal Penelitian Pendidikan Bahasa Indonesia, Daerah, dan Asing, 2(1), 118-131. https://doi.org/10.31540/silamparibisa.v2i1.331

Asnidar, A. (2018). Analisis Wacana Kritis Iklan Operator Seluler. Konfiks : Jurnal Bahasa dan Sastra Indonesia, 4(2). doi:10.26618/jk.v4i2.1336

Darma, Y. A. (2009). Analisis Wacana Kritis. Bandung: Yrama Widya.

Darmawan, F. (2006). Posmodernisme Kode Visual dalam Iklan Komersial. Mediator: Jurnal Komunikasi, 7(1), 103-114. https://doi.org/10.29313/mediator.v7i1.1219

Elevate. (2016). Sejarah Singkat Periklanan di Dunia. Jagoan Reklame. https://jagoanreklame.com/sejarah-singkat-periklanan-di-dunia/

Eriyanto. (2001). Analisis Wacana: Pengantar Analisis Teks Media. Yogyakarta: LKIS. 
Eriyanto. (2006). Analisis Wacana: Pengantar Analisis Teks Media. Yogyakarta: LKIS.

Fairclough, N. (1995). Critical Discourse Analysis: the Critical Study of Language. London and New York: Longman.

Hiariej, E. (2006). Perkembangan Kapitalisme Negara di Indonesia. Jurnal IImu Sosial dan IImu Politik, 10(1), 91-120.

Indah, N., \& Bakti, H. (2017). Analisis Tekstual dalam Konstruksi Wacana Berita Korupsi di Metro TV dan NET dalam Perspektif Analisis Wacana Kritis Norman Fairclough. Seloka: Jurnal Pendidikan Bahasa Dan Sastra Indonesia, 6(2), 123-129.

Jorgensen, M. W. \& Phillips, L. J. (2007). Analisis Wacana: Teori dan Metode. Yogyakarta: Pustaka Belajar.

Mahartika, L. (2019). Jenis-Jenis Iklan Berdasarkan Isi, Media dan Tujuannya. Liputan 6. https://www.liputan6.com/citizen6/read/3922906/jenis-jenis-iklanberdasarkan-isi-media-dan-tujuannya.

Noermanzah, Wardhana, D. E. C., Friantary, H., Arsyad, S. (2019). Joko Widodo's Rhetorical Structure in the Presidential Speeches for Addressing Educational Problems. International Journal of Scientific and Technology Research, 8(10).

Noermanzah, Emzir, \& Lustyantie, N. (2018). President Joko Widodo's Rhetorical Technique of Arguing in the Presidential Speeches of the Reform Era. International Journal of Applied Linguistics and English Literature, 7(5), 119. doi:10.7575/aiac.ijalel.v.7n.5p.117

Noermanzah, N. (2017). Struktur Kalimat Tunggal Bahasa Sindang di Kota Lubuklinggau dan Pengaruhnya dalam Pembelajaran Bahasa Indonesia. AKSIS: Jurnal Pendidikan Bahasa dan Sastra Indonesia, 1(1), 2. doi:10.21009/aksis.010101

Pertiwi. (2008). Representasi Ideologi dalam Iklan Cetak: Telaah atas Iklan "Rabbani" Edisi Ramadhan. Jurnal Dakwah, IX(I), 47-61.

Saputra, V. E., \& Widyatmoko, W. (2019). Pengaruh Kualitas Pesan Iklan dan Kreativitas Iklan Terhadap Daya Tarik Iklan "Udah Waktunya Pake GO-JEK - Vertibokek." Prologia, 3(1), 289-290. doi:10.24912/pr.v3i1.6253

Setianingrum, Y. (2019). Kreativitas dalam Desain Iklan Rokok di Jawa, 19301970an. Lembaran Sejarah, 9(2), https://jurnal.ugm.ac.id/lembaransejarah/article/view/23775. 
Tohir, M. (2016). Mengungkap Retorika Iklan melalui Pendekatan Semiotika Studi Kasus pada Iklan FedEx. Desain Komunikasi Visual, Manajemen Desain dan Periklanan (Demandia), 1(1), 35-36, doi:10.25124/demandia.v1i01.193

Utama, J. (2018). Daya Tarik Visual Sebagai Brand Recall Pada Iklan Televisi Studi Kasus Iklan Mizone 2012 Versi "Tilt." Jurnal Bahasa Rupa, 2(1), 4351. https://doi.org/10.31598/bahasarupa.v2i1.228

Zamzani, Z., Rahayu, Y. E., \& Maslakhah, S. (2017). Eksistensi Bahasa dalam Iklan Televisi Indonesia. Litera, 16(2), 249-264. https://doi.org/10.21831/ltr.v16i2.15971 